\title{
Microgreens: from trendy vegetables to functional food and potential nutrition security resource
}

\author{
F. Di Gioia1,a, S.A. Petropoulos², I.C.F.R. Ferreira ${ }^{3}$ and E.N. Rosskopf ${ }^{4}$ \\ ${ }_{1}^{1}$ Department of Plant Science, The Pennsylvania State University, University Park, PA 16802, USA; 2University of \\ Thessaly, Department of Agriculture, Crop Production and Rural Environment, 38446 N. Ionia, Magnissia, Greece; \\ 3Instituto Politécnico de Bragança, Centro de Investigação de Montanha (CIMO), Campus de Santa Apolónia, 5300- \\ 253 Bragança, Portugal; ${ }^{4}$ USDA-ARS, US Horticultural Research Laboratory, 2001 South Rock Rd., Fort Pierce, FL \\ 34945, USA.
}

\begin{abstract}
Starting as trendy high-value gourmet greens, today, microgreens have gained great popularity among consumers for their nutritional profile and high content of antioxidant compounds. Microgreens' nutritional profile is associated with the rich variety of colors, shapes, textural properties, and flavors obtained from sprouting a multitude of edible vegetable species, including herbs, herbaceous crops, and neglected wild edible species. Grown in a variety of soilless production systems, over the last five years in many urban and peri-urban areas of the world, microgreens have literally exploded as a cash crop produced in various protected culture systems and especially indoors through the use of artificial lighting systems. The ability to grow microgreens indoors in very small space, the short growth cycle required, and only minimum inputs required to produce them may allow the micro-scale production of fresh and nutritious vegetables even in areas that are considered food deserts. The current COVID-19 pandemic revealed the vulnerability of our food system and the need to address malnutrition issues and nutrition security inequality which could be exacerbated by potential future situations of emergency or catastrophe. Microgreens have great potential as an efficient food resilience resource, since they can provide essential nutrients and antioxidants. Using simple soilless production systems, seeds, and minimal inputs, nutrient-dense microgreens and shoots may be produced under different lighting conditions ranging from darkness to full sunlight or under artificial lighting in controlled environmental conditions, providing a rich source of essential nutrients and antioxidant compounds in a very short time. Moreover, using simple agronomic techniques, it is possible to produce biofortified or tailored functional micro-vegetables that could address specific dietary needs and/or address micronutrient deficiencies and nutrition security issues in emergency situations or limiting environmental conditions.
\end{abstract}

Keywords: agrobiodiversity, biofortification, food deserts, food resilience, human health, malnutrition, food emergency, nutrition security

\section{INTRODUCTION}

From a market standpoint, microgreens could be defined as high-value gourmet greens, commonly used by chefs to add value to any dish or culinary preparation by simply exploiting the distinctive aesthetical quality and/or sensorial properties that microgreens can provide (Di Gioia et al., 2017a; Renna et al., 2017). Over the past decade, microgreens have also gained increasing popularity among consumers for their rich nutritional profile and content of health-beneficial bioactive compounds (Di Gioia et al., 2017a; Kyriacou et al., 2016). Research conducted over the past few years examining the composition of microgreens as a function of genotype or of preharvest and postharvest factors continues to identify interesting nutritional and secondary metabolite profiles of selected microgreen species and of microgreens in general (Ghoora et al., 2020; Kopsell et al., 2012; Kyriacou et al., 2019; Sun et al., 2013; Xiao,

aE-mail: fxd92@psu.edu 
2013; Xiao et al., 2012, 2014, 2015, 2016).

From a technical point of view, microgreens could be defined as young fresh shoots produced at relatively high density from sprouting seeds of a variety of plant species including vegetables, grains, pseudo-grains, pulses, herbs, and wild edible species. The young shoots are harvested and consumed at the earliest growth stages, generally corresponding to the full development of cotyledonary leaves or to the appearance of the first true leaves (Benincasa et al., 2019; Di Gioia et al., 2017a; Kyriacou et al., 2016). Microgreens do not have a legal definition yet, and often have been compared to sprouts or baby leaf greens; however, they have distinctive characteristics compared to the above mentioned in terms of production techniques, harvesting stage and method, and most importantly in what constitutes the edible portion, and therefore should be considered as a separate category of greens (Di Gioia et al., 2017a, b; Kyriacou et al., 2016).

Depending on the species and growing conditions, microgreens' cycle from sowing to harvest may range from 6 to 7 days to 21-28 days. They can be grown in soil or soilless systems, with or without the use of fertilizers, and may be grown in the presence of natural light, with supplementary artificial lighting, using exclusively artificial lighting, or even in dark conditions when the production of etiolated greens is intended (Di Gioia et al., 2017a). If using seeds of good quality, microgreens can be produced with very limited inputs, and following both conventional and organic production methods. Given the increasing demand for organic produce and considering the short crop cycle, it is, in fact, relatively easy to produce microgreens organically. Even when using soilless organic growing media, if non-synthetic inputs are used, and organic label regulations are met, the production can be certified as organic in the USA as well as in Europe (Di Gioia and Rosskopf, 2021).

Another aspect that makes microgreens quite unique and increasingly popular is the variety of species that can be used to produce microgreens. The variety of edible plant species and populations suitable to produce microgreens continues to expand and constitutes a rich assortment of shapes, textures, and colors which are associated with unique sensorial and nutritional properties that are distinctive of the genetic material used (Di Gioia et al., 2017a, 2020a; Kyriacou et al., 2016). Microgreens offer, for example, a new opportunity to recover and create high-value products using neglected genetic resources, local landraces, and populations characterized by particular quality attributes and unique nutritional profiles (Chatzopoulou et al., 2020; Corrêa et al., 2020b, 2020a; Di Gioia and Santamaria, 2015). Such opportunity pairs well with the continuous search for innovations and new products in the food industry and with consistently increasing consumer demands for fresh, nutrient-rich and healthy vegetable products, as well as with the need to address food and nutrition security issues in low- and middle-income countries or in food deserts of high-income countries (Byker Shanks et al., 2020; Di Gioia et al., 2019).

\section{MALNUTRITION AND NUTRITION SECURITY}

Although great progress has been achieved over the past half century in enhancing food security, malnutrition and nutrition security are still a major challenge affecting billions of people across the world, with the current COVID-19 pandemic further exacerbating this situation (Food and Agriculture Organisation - FAO, 2012; Nutrition, 2020).

In the past, significant emphasis has been placed on solving the issue of food insecurity and addressing hunger considering the provision of adequate calorie intake. Today, with many countries experiencing the so called "triple burden" of malnutrition in which people are affected by undernutrition, obesity, and other diet-related diseases, more emphasis is given to the concept of nutrition security which goes beyond and encompasses the whole concept of food security (Ingram, 2020).

According to FAO, nutrition security is achieved "when secure access to an appropriately nutritious diet is coupled with a sanitary environment and adequate health services and care, in order to ensure a healthy and active life for all household members. Nutrition security differs from food security in that it also considers the aspects of adequate caregiving practices, health and hygiene, in addition to dietary adequacy" (FAO, IFAD, UNICEF, WFP, 2020). From this perspective, addressing nutrition security is more challenging and complex than 
addressing food security, and adequate governance and actions on many aspects of daily life are required at the community, regional, national, and international level to address nutritional and consequent health related inequalities (Nutrition, 2020). Therefore, while the roadmap to achieve a global status of nutrition security is long and complex, improving the availability of fresh and nutrient-dense greens in regions and areas most affected by undernutrition or malnutrition is a key priority and can contribute, at least in part, to solving this long-standing global social and health issue. Although various assistance programs are implemented in the most critical situations, including situations of emergency, food and nutrition resilience and the ability to provide adequate food and nutrition for our own use and health may be a key factor in overcoming these disparities.

\section{COVID-19, EMERGENCY SITUATIONS, AND MICROGREENS AS A POTENTIAL NUTRITION SECURITY RESOURCE}

While the COVID-19 pandemic is not considered a food emergency, in most cases, it certainly disrupted the food chain and as a global health emergency, had a significant impact on food and nutrition security and even when it did not threaten food security, it had a substantial impact on food purchase and consumers habits toward food and nutrition (Goetz et al., 2020; Naja and Hamadeh, 2020). In many cases, the COVID-19 pandemic had a negative impact on the diet (Butler and Barrientos, 2020), and often worsened or challenged the nutrition security of the most vulnerable segments of the global populations (Pérez-Escamilla et al., 2020). In other cases, the pandemic positively influenced people's attention and attitude toward food nutritional quality and origin. The COVID-19 pandemic contributed to increased consumer awareness of the strict association between agriculture, food origin, nutrition and human health, and many of people began considering more carefully their life style and dietary habits, e.g., they increased consumption of fruits and vegetables, and started paying more attention to bioactive compound content in their food (Shahidi and Costa de Camargo, 2021). Some consumers also changed their attitude toward food origin and while many started to buy more locally produced food, others revived the concept of the so called 'victory gardens' of the past and started producing their own fresh vegetables after thinking their food and nutrition security was threatened by the pandemic (Worstell, 2020). However, not everyone has the luxury of purchasing fresh vegetables from a local community support agriculture (CSA) operation, a local farm, or even has a garden big enough to grow their own vegetables, and COVID-19 exacerbated inequalities even in terms of availability and access to public green spaces (Geary et al., 2021). Nevertheless, as the pandemic forced many to stay home and limit social activities, a new trend was observed and an increasing number of people started producing microgreens at home for self-consumption (Di Gioia, 2020).

For all the characteristics mentioned above, microgreens offer many unique opportunities, and may represent a simple short-term solution, even partially, to address nutrition insecurity and malnutrition issues that could be addressed at the household level, especially under situations of emergency like the current pandemic, when the supply of fresh and nutritious food may be limited or altered.

The COVID-19 pandemic and its impact on every aspect of our daily lives, including our diet and nutrition, made it clear that we are all vulnerable and that our food system has vulnerabilities and may not be as secure as thought before the pandemic. This prompted many to seek solutions to address their own nutritional security even for a short period of time, and while it is fairly easy to stock up on food with a long shelf-life, e.g., grains, cereals, pulses, securing the availability of fresh and highly nutritious food like vegetables is more challenging.

Microgreens, however, may be a good short-term solution to guarantee adequate human nutrition at the household level in situations of emergency. Besides being appealing for their nutritional profile, microgreens are gaining popularity for the opportunity they offer to produce high-quality fresh and healthy greens year-round, in relatively short time, using small spaces, under almost any conditions. In fact, microgreens may be produced at the commercial level in open-field, in high tunnels, specialized greenhouses and indoor production facilities, including vertical farm facilities in urban and peri-urban settings, or in non-conventional growing spaces such as a cruise ship, a growing area next to the kitchen of a restaurant, on a 
rooftop or underground the center of a metropolitan area, or even in a supermarket, and can also be produced for self-consumption at household level using spaces that range from the backyard garden to the basement of a house, or on the windowsill of a flat (Di Gioia and Santamaria, 2015; Di Gioia et al., 2017a).

Figure 1 provides an example of how it is possible to produce microgreens at the household level in relatively small space and using very simple tools easily available in a kitchen. Besides seeds, growing trays, and a growth medium, which could be constituted by a common peat or peat and perlite growth mix, or by alternative materials, including recycled microbiologically safe material (Di Gioia et al., 2017b).

Given all these characteristics, microgreens have also been proposed as a source of fresh food and essential nutrients for astronauts engaged in long-term space missions (Kyriacou et al., 2017). Researchers at NASA and the European Space Agency (ESA) are in fact investigating this option and are trying to address issues associated with growing plants in microgravity and assuring maximum food safety for the astronauts.

Moreover, while microgreens are considered functional food products for their high content of nutrients and bioactive compounds (Di Gioia et al., 2017a; Kyriacou et al., 2016), recent studies have also demonstrated the opportunity to use agronomic biofortification techniques to further enhance their nutritional value increasing for example the content of specific essential micronutrient or boosting the content of bioactive compounds (Germ et al., 2019; Di Gioia et al., 2019, 2020b; Petropoulos et al., 2017).

In this context, microgreens may be used as functional food to enhance nutrition security under current conditions as well as in different predictable or unpredictable situations of emergency or catastrophes potentially caused by natural events, wars, and/or human errors. Nutrition security microgreen production kits including seeds could be stored relatively easily and in small spaces to prevent situations of emergency or alternatively could be distributed to vulnerable segments of the population as a short-term nutrition security resource. Under such circumstances, a variety of fresh and nutrient-rich microgreens could be grown in very limited space and with minimum inputs, providing a source of minerals, vitamins, and antioxidants in a relatively short time.

\section{CONCLUSIONS}

Nutrition security is a long-term global challenge affecting billions of people at the global level. This challenge requires immediate adequate action and the development of solutions at various levels. The current COVID-19 pandemic exacerbated nutritional security inequalities, highlighting the importance of developing solutions to reduce the potential negative impact on human nutrition of future predictable or unpredictable emergency situations or catastrophes. Microgreens, for the diversity of species and associated nutritional properties, visual quality, and palatability, and for their simple and relatively short growing cycle, which requires limited inputs and relatively small space, represent a unique source of nutrients, with functional properties that could be used to address specific dietary needs and malnutrition issues under normal conditions or in emergency situations. For all these characteristics, and because of the ability to be grown under variable conditions, even in darkness, microgreens could constitute a tremendous nutrition security resource. Nevertheless, more research is needed to further assess their nutritional value, acceptability, and efficacy in addressing malnutrition issues, and finally to develop an easily deployed microgreen survival growing kit which could be used as a short-term solution in situations of food emergency. 

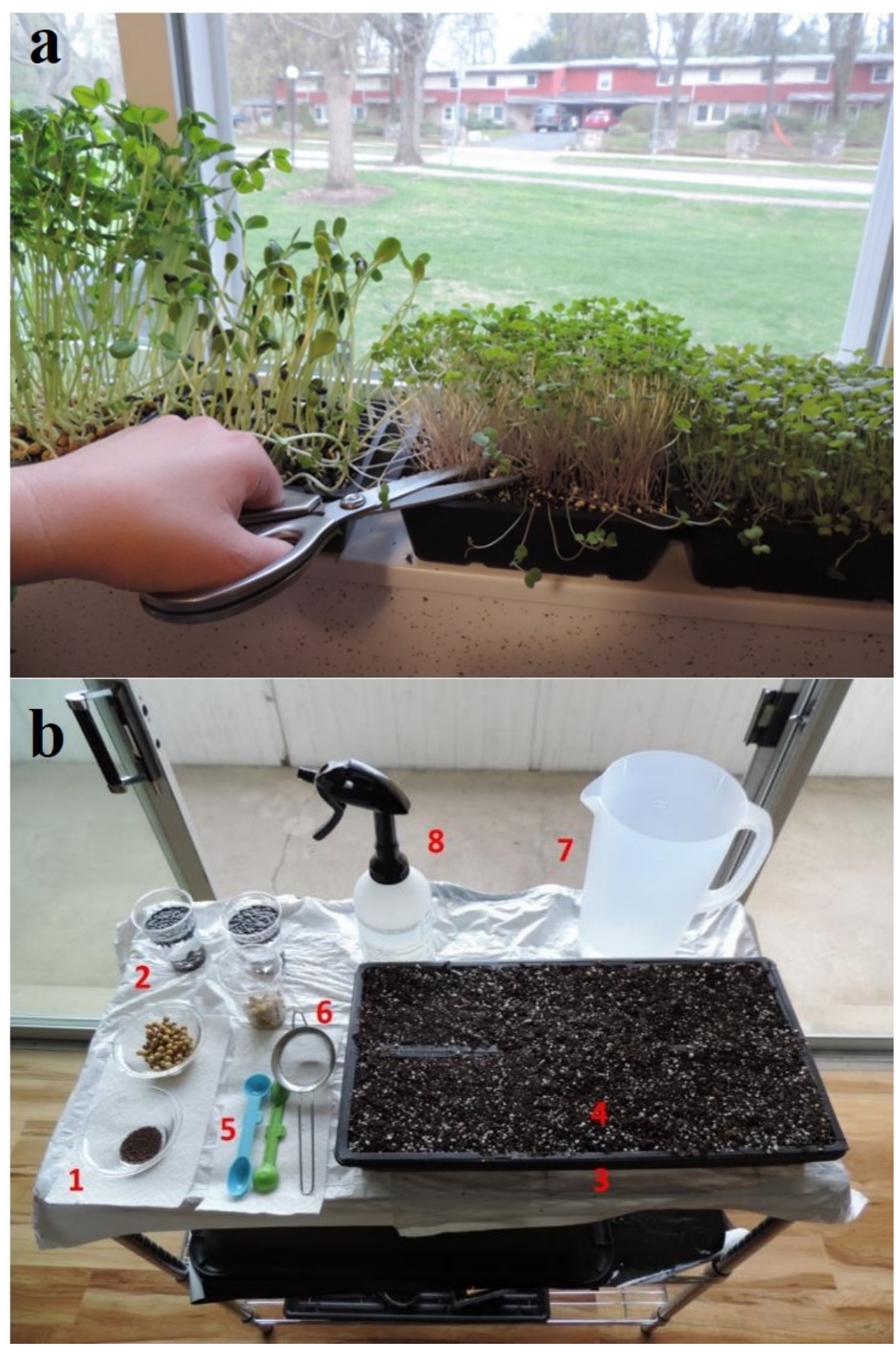

Figure 1. Example of microgreens production for self-consumption at the household level (a) and simple kitchen tools and material needed to start a cultivation of microgreens at home (b): 1) microgreens seeds, 2) small cups or containers to soak the seeds in water, 3 ) growth trays, 4) growing medium (in this case is a peat and perlite mix), 5) measuring cups/spoons to measure the right amount of seeds per tray, 6) a small colander, 7) a pitcher, and 8) a spray bottle. Photo credits: Francesco Di Gioia.

\section{ACKNOWLEDGEMENTS}

Contribution of F. Di Gioia have been supported by the Food Resilience in the Face of Catastrophic Global Events grant funded by Open Philanthropy and by the USDA National Institute of Food and Agriculture and Hatch Appropriations under Project \#PEN04723 and Accession \#1020664. 


\section{Literature cited}

Benincasa, P., Falcinelli, B., Lutts, S., Stagnari, F., and Galieni, A. (2019). Sprouted grains: a comprehensive review. Nutrients 11 (2), 421 https://doi.org/10.3390/nu11020421. PubMed

Butler, M.J., and Barrientos, R.M. (2020). The impact of nutrition on COVID-19 susceptibility and long-term consequences. Brain Behav Immun 87, 53-54 https://doi.org/10.1016/j.bbi.2020.04.040. PubMed

Byker Shanks, C., Calloway, E.E., Parks, C.A., and Yaroch, A.L. (2020). Scaling up measurement to confront food insecurity in the USA. Transl Behav Med 10 (6), 1382-1389 https://doi.org/10.1093/tbm/ibaa112. PubMed

Chatzopoulou, E., Carocho, M., Di Gioia, F., and Petropoulos, S.A. (2020). The beneficial health effects of vegetables and wild edible greens: the case of the Mediterranean diet and its sustainability. Appl. Sci. (Basel) 10 (24), 9144 https://doi.org/10.3390/app10249144.

Corrêa, R.C.G., Di Gioia, F., Ferreira, I.C.F.R., and Petropoulos, S.A. (2020a). Wild greens used in the Mediterranean diet. In The Mediterranean Diet (Elsevier), p.209-228.

Corrêa, R.C.G., Di Gioia, F., Ferreira, I., and Petropoulos, S.A. (2020b). Halophytes for future horticulture: The case of small-scale farming in the Mediterranean basin. Halophytes Futur. Hortic. From Mol. to Ecosyst. Towar. Biosaline Agric., p.1-28.

Di Gioia, F. (2020). A Step-By-Step Guide for Growing Microgreens at Home.

Di Gioia, F., and Rosskopf, E.N. (2021). Organic hydroponics: a US reality challenging the traditional concept of "organic" and "soilless" cultivation. Acta Hortic. 1321, 275-282. https://doi.org/10.17660/ActaHortic.2021. 1321.36.

Di Gioia, F., and Santamaria, P. (2015). Microgreens - Novel Fresh and Functional Food to Explore All the Value of Biodiversity (Bari: Eco-logica s.r.l.).

Di Gioia, F., Renna, M., and Santamaria, P. (2017a). Sprouts, microgreens and "baby leaf" vegetables. In Food Engineering Series (Boston, MA: Springer), p.403-432.

Di Gioia, F., De Bellis, P., Mininni, C., Santamaria, P., and Serio, F. (2017b). Physicochemical, agronomical and microbiological evaluation of alternative growing media for the production of rapini (Brassica rapa L.) microgreens. J Sci Food Agric 97 (4), 1212-1219 https://doi.org/10.1002/jsfa.7852. PubMed

Di Gioia, F., Petropoulos, S.A.S.A., Ozores-Hampton, M., Morgan, K., and Rosskopf, E.N.E.N. (2019). Zinc and iron agronomic biofortification of Brassicaceae microgreens. Agronomy (Basel) 9 (11), 677 https://doi.org/10.3390/ agronomy9110677.

Di Gioia, F., Tzortzakis, N., Rouphael, Y., Kyriacou, M.C., Sampaio, S.L., Ferreira, I.C.F.R., and Petropoulos, S.A. (2020a). Grown to be blue - antioxidant properties and health effects of colored vegetables. Part II: leafy, fruit, and other vegetables. Antioxidants (Basel) 9 (2), 1-41 https://doi.org/10.3390/antiox9020097. PubMed

Di Gioia, F., Pinela, J., de Haro Bailón, A., Fereira, I.C., and Petropoulos, S.A. (2020b). The dilemma of "good" and "bad" glucosinolates and the potential to regulate their content. In Glucosinolates: Properties, Recovery, and Applications, C.M. Galanakis, ed. (London: Academic Press), p.1-45.

FAO, IFAD, UNICEF, WFP. (2020). Food Security and Nutrition in the World.

Food and Agriculture Organisation (FAO). (2012). The State of Food Insecurity in the World 2012. FAO 56 http://ftp.fao.org/docrep/fao/011/i0291e/i0291e00.pdf.

Geary, R.S., Wheeler, B., Lovell, R., Jepson, R., Hunter, R., and Rodgers, S. (2021). A call to action: improving urban green spaces to reduce health inequalities exacerbated by COVID-19. Prev Med 145, 106425 https://doi.org/10. 1016/j.ypmed.2021.106425. PubMed

Germ, M., Stibilj, V., Šircelj, H., Jerše, A., Kroflič, A., Golob, A., and Maršić, N.K. (2019). Biofortification of common buckwheat microgreens and seeds with different forms of selenium and iodine. J Sci Food Agric 99 (9), 4353-4362 https://doi.org/10.1002/jsfa.9669. PubMed

Ghoora, M.D., Babu, D.R., and Srividya, N. (2020). Nutrient composition, oxalate content and nutritional ranking of ten culinary microgreens. J. Food Compos. Anal. 91, 103495 https://doi.org/10.1016/j.jfca.2020.103495.

Goetz, S.J., Meadowcroft, D., Schmidt, C., Mitra, P., and Di Gioia, F. (2020). In the Mid-Atlantic Fruit and Vegetable Industry, Market Workers and Local Specialized Freight Truckers May be at Greatest Risk. NERCRD COVID-19 Issues Br., p.1-9.

Ingram, J. (2020). Nutrition security is more than food security. Nat. Food 1 (1), 2-2 https://doi.org/10.1038/ s43016-019-0002-4.

Kopsell, D.A., Pantanizopoulos, N.I., Sams, C.E., and Kopsell, D.E. (2012). Shoot tissue pigment levels increase in 'Florida Broadleaf' mustard (Brassica juncea L.) microgreens following high light treatment. Sci. Hortic. 
(Amsterdam) 140, 96-99 https://doi.org/10.1016/j.scienta.2012.04.004.

Kyriacou, M.C., Rouphael, Y., Di Gioia, F., Kyratzis, A., Serio, F., Renna, M., De Pascale, S., and Santamaria, P. (2016). Micro-scale vegetable production and the rise of microgreens. Trends Food Sci. Technol. 57, 103-115 https://doi.org/10.1016/j.tifs.2016.09.005.

Kyriacou, M.C., De Pascale, S., Kyratzis, A., and Rouphael, Y. (2017). Microgreens as a component of space life support systems: a cornucopia of functional food. Front Plant Sci 8, 1587 https://doi.org/10.3389/fpls. 2017.01587. PubMed

Kyriacou, M.C., El-Nakhel, C., Graziani, G., Pannico, A., Soteriou, G.A., Giordano, M., Ritieni, A., De Pascale, S., and Rouphael, Y. (2019). Functional quality in novel food sources: genotypic variation in the nutritive and phytochemical composition of thirteen microgreens species. Food Chem 277, 107-118 https://doi.org/10. 1016/j.foodchem.2018.10.098. PubMed

Naja, F., and Hamadeh, R. (2020). Nutrition amid the COVID-19 pandemic: a multi-level framework for action. Eur J Clin Nutr 74 (8), 1117-1121 https://doi.org/10.1038/s41430-020-0634-3. PubMed

Nutrition. (2020). Global Nutrition Report.

Pérez-Escamilla, R., Cunningham, K., and Moran, V.H. (2020). COVID-19 and maternal and child food and nutrition insecurity: a complex syndemic. Matern Child Nutr 16 (3), e13036 https://doi.org/10.1111/mcn.13036. PubMed

Petropoulos, S., Di Gioia, F., and Ntatsi, G. (2017). Vegetable organosulfur compounds and their health promoting effects. Curr Pharm Des 23 (19), 2850-2875 https://doi.org/10.2174/1381612823666170111100531. PubMed

Renna, M., Di Gioia, F., Leoni, B., Mininni, C., and Santamaria, P. (2017). Culinary assessment of self-produced microgreens as basic ingredients in sweet and savory dishes. J. Culin. Sci. Technol. 15 (2), 126-142 https://doi.org/ 10.1080/15428052.2016.1225534.

Shahidi, F., and Costa de Camargo, A. (2021). Trends in food bioactives in the COVID-19 pandemic year. J. Food Bioact. 13.

Sun, J., Xiao, Z., Lin, L.-Z., Lester, G.E., Wang, Q., Harnly, J.M., and Chen, P. (2013). Profiling polyphenols in five Brassica species microgreens by UHPLC-PDA-ESI/HRMS(n.). J Agric Food Chem 61 (46), 10960-10970 https://doi.org/10. 1021/jf401802n. PubMed

Worstell, J. (2020). Ecological resilience of food systems in response to the COVID-19 crisis. J. Agric. Food Syst. Community Dev. 9, 1-8 https://doi.org/10.5304/jafscd.2020.093.015.

Xiao, Z. (2013). Nutrition, sensory, quality and safety evaluation of a new specialty produce: microgreens. Univ. Maryl. 1, 145.

Xiao, Z., Lester, G.E., Luo, Y., and Wang, Q. (2012). Assessment of vitamin and carotenoid concentrations of emerging food products: edible microgreens. J Agric Food Chem 60 (31), 7644-7651 https://doi.org/10.1021/jf300459b. PubMed

Xiao, Z., Lester, G.E., Luo, Y., Xie, Z.K., Yu, L.L., and Wang, Q. (2014). Effect of light exposure on sensorial quality, concentrations of bioactive compounds and antioxidant capacity of radish microgreens during low temperature storage. Food Chem 151, 472-479 https://doi.org/10.1016/j.foodchem.2013.11.086. PubMed

Xiao, Z., Lester, G.E., Park, E., Saftner, R.A., Luo, Y., and Wang, Q. (2015). Evaluation and correlation of sensory attributes and chemical compositions of emerging fresh produce: microgreens. Postharvest Biol. Technol. 110, 140-148 https://doi.org/10.1016/j.postharvbio.2015.07.021.

Xiao, Z., Codling, E.E., Luo, Y., Nou, X., Lester, G.E., and Wang, Q. (2016). Microgreens of Brassicaceae: mineral composition and content of 30 varieties. J. Food Compos. Anal. 49, 87-93 https://doi.org/10.1016/j.jfca. 2016.04.006. 
